\title{
¿QUE ES AMÉRICA LATINA? CONCEPTO Y EXTENSIÓN DE SU NÚCLEO DE CERTEZA POSITIVA
}

\author{
WHAT IS LATIN AMERICA? CONCEPT AND EXTENSION OF ITS CORE OF POSITIVE CERTAINTY
}

Patricia Sánchez-Recio ${ }^{1}$

\section{Resumen}

El propósito es delimitar conceptualmente, y por tanto establecer los países que, como mínimo, deben conformar la muestra de un estudio que indique versar sobre América Latina. Se defiende la tesis que identifica el núcleo de certeza positiva del concepto "Latinoamérica", con los países pertenecientes a la América Hispánica. Se sustenta dicha tesis en el hecho de que este conjunto de países son el producto del mismo camino a la modernidad, lo que los ha ubicado como parte de la zona periférica mundial, con su consecuente situación de dependencia.

\section{Palabras clave}

América Latina, Concepto, Núcleo de certeza positiva, Modernidad, Dependencia.

\section{Abstract}

The purpose is to delimit conceptually, and therefore to establish the countries that, at least, must conform the sample of a study that indicates to turn on Latin America. The thesis that identifies the core of positive certainty of the concept "Latin America" is defended, with the countries belonging to Hispanic America. This thesis is based on the fact that this group of countries are the product of the same path to modernity, which has placed them as part of the peripheral world zone, with its consequent dependence situation.

\section{Keywords}

Key Words: Latin America, Concept, Nucleus of positive certainty, Modernity, Dependency.

\footnotetext{
${ }^{1}$ Universidad de Murcia (España). Correo electrónico: p.sanchezrecio@um.es.
} 


\section{Introducción}

El propósito es delimitar conceptualmente, y por tanto establecer los países que, como mínimo, deben conformar una muestra el estudio que indique versar conceptualmente ${ }^{1}$ sobre América Latina. Se pretende, de este modo, dar apoyo conceptual a todo discurso que esté dirigido a analizar comparativamente a un conjunto de naciones que, de manera abstracta y con múltiples significantes, se conocen como América Latina.

$\mathrm{Al}$ respecto, en estudios de toda la gama de las ciencias sociales, que centran su objeto de estudio en América Latina, está presente una especie de angustia que se representa en obviar su existencia o en discutir su identidad e integridad y buscar configurarla a toda costa ${ }^{2}$. A los Latinoamericanos nos tortura la idea de saber qué somos (Zea, 1977). ¿Realmente aparecen como evidentes un conjunto de elementos, que además de la proximidad geográfica, homogeneizan tal diversidad y permiten un tratamiento científico en conjunto?, ¿Qué países componen de manera invencible este conjunto?

Al formular estas preguntas, como marco general, no se pretende obviar una primera proposición que se da por cierta: América Latina existe. Existe como conjunto y posee cierta unidad. Yendo más allá, se puede afirmar que América Latina no es solo una expresión de uniformidad, es una expresión de unidad. Siguiendo al profesor Touraine (1989), se parte de la hipótesis que "existe un modo latinoamericano de desarrollo, es decir, una combinación, propia de ese continente, de racionalismo económico y de movilización política y social" (p.23). Pero realmente, ¿Qué significa en el análisis "el contexto Latinoamericano"? ¿Cuáles son sus condiciones de posibilidad? ¿Cuáles son las grandes líneas que hacen comparables a estas distintas naciones; a tan heterogéneos pueblos? Como se verá, la tesis que se propone para dar respuesta a estas preguntas estará informada por importantes vectores que construyen su situación especial: la peculiaridad de su evolución histórica y su consecuente subdesarrollo.

Por supuesto, las conclusiones que se puedan ofrecer no tienen la pretensión ni mucho menos de resolver de

\footnotetext{
1 En diferenciación de una muestra simplemente estadística, por eje mplo, que podría estar conformada por unos u otros países, siempre y cuando cumpla con los criterios muéstrales.

2 Al respecto ver las disertaciones de autores como Rodó (1967), Martí (2002), Lastarria (1868), Bilbao (1864), Vasconcelos (1927), y más recientemente: Zea (1977), Villegas (1972), Roig (1981), MiróQuesada (1974), Ribeiro (1986), Ardao (1993), y tantos más.
}

manera definitiva la cuestión, su objeto es mucho más simple, el cual no es otro que el de justificar la selección de unos países como muestra lo suficientemente significativa, en desmedro de otros y que, de este modo, se permita predicar las conclusiones generales obtenidas al sujeto América Latina. En este sentido se defenderá la tesis que identifica el núcleo de certeza positiva del concepto (NCP) de "Latinoamérica" con los países pertenecientes a la América Hispánica.

Cuando hablamos de "núcleo de certeza positiva", nos referimos al grado de determinación que presenta un concepto. En este caso es viable fijar el significado y aplicar el concepto a un caso particular de la realidad. Por el contrario, la "zona de penumbra" se refiere a la incertidumbre o controversia respecto del concepto. Nos referimos por tanto al gobierno de su significación.

\section{Problematización del término}

Siguiendo el modelo platónico, expresado en el dialogo del Menón, donde Sócrates resalta la imposibilidad de reconocer o asignar facultades a algo, sin antes saber, en un sentido fuerte, que es $s^{3}$, se propone primero reconocer, siquiera medianamente, qué es América Latina, como condición necesaria para saber cómo se desarrollan sus procesos sociales (económicos, jurídicos, administrativos, políticos y otros). Por simple que pueda parecer, el concepto mismo de América Latina representa un problema. No es inútil pues intentar precisarlo, recordar su historia y hasta criticar su uso, y tratar de justificar por qué se escogen unos países en detrimentos de otros.

De empleo corriente en el lenguaje internacional, como término no tiene todo el privilegio del rigor. Dos palabras que a veces parecen ser fuente de confusión más que instrumento de delimitación preciso y, por ende, de fuerte construcción teórica o conceptual. Sin duda, la vaguedad es una característica del concepto América Latina. Así, hay casos respecto a los cuales su aplicación no está definida con precisión. No es el caso de que no se pueda precisar su significado, sino que se duda sobre dónde termina su campo de aplicación. No hay un límite preciso que permita deslindar la aplicación de la inaplicación de este concepto.

Valga recordar que, en todo término vago, como América Latina se pueden distinguir tres zonas: a) la zona central o núcleo de certeza positiva, donde la aplicación del término no ofrece dudas; b) la zona o núcleo de certeza 3 Se establece en el sentido de naturaleza o esencia de algo. 
negativa, respecto del cual es claro que el término no se aplica; c) la zona de penumbra que cubre aquellos casos respecto de los cuales su aplicación es dudosa.

El objetivo, por tanto, con la justificación debida es definir qué naciones componen el núcleo duro o de certeza positiva del concepto de "América Latina".

La respuesta más accesible y menos problemática pareciera ser la geográfica. Geográficamente América latina es el conjunto de los países de América del Sur y América Central (incluyendo México), es decir, todo el hemisferio con exclusión de América del Norte. Tal postura de plano no puede ser del todo correcta y, como se verá más adelante, genera confusión. En efecto, Latinoamérica suele ser un término con el que se generaliza a países de América Central como Belice, colonia británica y vigente miembro de la mancomunidad británica de naciones; o países de América del Sur como Surinam o la Guyana Francesa. También se suele aplicar indiscriminadamente a las islas del Caribe, de habla inglesa y holandesa, que reclaman independencia de trato, en reivindicación de su propia identidad cultural y geopolítica ${ }^{4}$.

América Latina es una región de gran diversidad, habitada por 626 millones de personas que hablan español, portugués, inglés, francés y cerca de 400 lenguas indígenas. A pesar de esto, hay quienes afirman que la América Latina es aquella que cubre exclusivamente las naciones de cultura latina de América. Al respecto encontramos casos como Canadá, que tal vez sea más latina que la Guyana, o Puerto Rico, estado libre asociado de Estados Unidos que, obviamente, no parte del subconjunto latinoamericano, o Guyana donde se habla inglés; y el Surinam de habla holandesa que para varios geógrafos forma parte de América Latina.

Como se puede evidenciar, se genera en la literatura geográfica, sociológica y geopolítica, una especie de "zona gris" respecto a qué naciones componen la "América

\footnotetext{
4 Al respecto sin embargo, es importante resaltar como la Comisión Económica para América latina - CEPAL- pareciera aplicar este criterio, ya que en sus estudios estadísticos presenta el conjunto de 46 países correspondientes a la totalidad de América Central y del Sur: Anguila, Antigua y Barbuda, Antillas Neerlandesas, Argentina, Aruba, Bahamas, Barbados, Belice, Bolivia, Brasil, Chile, Colombia, Costa Rica, Cuba, Dominica, Ecuador, El Salvador, Granada, Guadalupe, Guatemala, Guyana, Guyana Francesa, Haití, Honduras, Islas Vírgenes Británicas, Islas Caimán, Islas Malvinas (Falklands), Islas Turcas y Caicos, Islas Vírgenes de los Estados Unidos, Jamaica, Martinica, México, Montserrat, Nicaragua, Panamá, Paraguay, Perú, Puerto Rico, República Bolivariana de Venezuela, República Dominicana, Saint Kitts y Nevis, Santa Lucía, San Vicente y Las Granadinas, Suriname, Trinidad y Tabago y Uruguay.
}

Latina" y cuales no. En el fondo, todo depende de cómo se conceptualice este término. Si se entiende como las naciones pertenecientes al hemisferio americano donde se infundió la cultura latina, o se refiere a las antiguas colonias de países europeos donde se hablan lenguas romances, es decir, derivadas del latín (España, Portugal y Francia); la extensión del término también varía si se entiende como el conjunto de naciones de América Central y Suramérica, o si incluimos o excluimos el Caribe.

Aparte de esto, el epíteto "Latina", sin duda alguna cuenta con una justificación histórica y de pretensiones hegemónicas. En Francia, bajo Napoleón III, se impuso este nombre con el fin de influir en las naciones "latinas" de América, interfiriendo en la égida de las naciones de la península Ibérica y detener igualmente la expansión de los Estados Unidos. De este modo, crear un bloque que hiciera contrapeso al bloque anglo (Torres, 2016).

La latinidad tenía la ventaja de borrar los vínculos particulares con España y otorgar un contexto de justificación a una intervención francesa, sobre naciones que consideraba hermanas dentro de la tradición latina y romanista. Esa latinidad se opone de este modo al pasado colonial español, que prefería el término América Hispánica, donde prevalecían los derechos de la madre patria $^{5}$. Igualmente se hace un término que se opone a un panamericanismo norteamericano, como movimiento que pretende fomentar las relaciones y la colaboración entre los Estados de América, bajo una peculiar y subyugante vinculación entre Estados Unidos y el resto de las repúblicas del continente. Paradójicamente, frente a esta perspectiva, surge otra que identifica a América Latina con la parte del continente no norteamericana; en rechazo a la generalización de identidad entre Estados Unidos y América.

Así, Iberoamérica, Hispanoamérica, Indoamérica, Amerindia, Euroindia y varios más han sido términos en competición por la denominación de un pedazo sumamente importante de territorio ${ }^{6}$. Sin embargo, se reitera, se ha impuesto "Latinoamérica" o "América Latina", nombre usado por Napoleón III y refrendado posteriormente por Charles de Gaulle, como expresión 5 Valga advertir que el hispanoamericanismo no es meramente una nostalgia colonial, sino una reacción antiimperialista, por ejemplo contra las pretensiones napoleónicas en México.

6 Todos estos términos no se refieren exclusivamente al territorio entendido como espacio geográfico o estatal. También pueden reseñar al territorio como relación social en el espacio. Por ejemplo Indoamérica pretende conceptualizar un conjunto social, una comunidad integrada por un componente étnico o racial. 
de un intento imperialista cultural encabezado por las antiguas Galias que restauraría su maltrecho prestigio en el mundo de habla romance (Ruiz-Gaytan, 2002).

Más allá de posturas geográficas - físicas o sociales culturales, o lingüísticas, podríamos pensar en descubrir una identidad subcontinental fuerte, construida a partir de múltiples relaciones, ya sea que se refieran a una cultura común o a vínculos de otra naturaleza. No obstante, la diversidad misma de las naciones latinoamericanas, su realidad tan difícilmente asequible, amenaza con menospreciar esta justificación. La escasa densidad de las relaciones económicas y hasta culturales de naciones que, durante casi dos siglos de vida independiente, se han dado la espalda una a otras, las enormes disparidades entre países no favorecen una real conciencia unitaria.

Seguimos en el problema, ¿qué abarca este concepto tan ampliamente usado y aceptado hoy en día? Como hemos visto, las evidencias del sentido común desaparecen pronto. Las disparidades entre países saltan a la vista. Sin embargo, si bien la definición Latina de un subcontinente no abarca integral ni adecuadamente realidades multiformes y en evolución, no por ello se puede abandonar teóricamente un concepto con tan amplio espectro de representación, y con una gran potencialidad como matriz reflexiva. Se reitera, América Latina existe.

Estos señalamientos tienen por único objeto subrayar que el concepto América Latina no es ni plenamente social - cultural, ni solamente físico - geográfico. Que es un concepto especialmente vago y ambiguo, pero que no por ello puede ser desechado, o sea un asunto sobre el cual ya no valga la pena discurrir. Como categoría analítica América Latina es una abstracción universal que sin duda permite, en el lenguaje, expresar situaciones particulares y concretas. Estas situaciones, pueden ser analizadas con igual instrumental teórico que el empleado para las naciones del centro del sistema capitalista, en tanto son, precisamente, parte de éste y comparten una misma lógica de funcionamiento. La diferencia está, en cambio, en la historia de unas y de otras (Ansaldi, 2000) ${ }^{7}$. Al respecto, es posible adherirse a lo expresado por el profesor Touraine (1989), cuando afirma que América Latina "define su especificidad a partir de su modo de desarrollo, su forma

\footnotetext{
7 Al respecto se resalta que el análisis histórico concreto del concepto "América Latina" introduce elementos enriquecedores al mero análisis lógico - constructivo. Como se verá, situaciones como la dependencia, la complejidad de las relaciones étnicas y de clases, las modalidades de relación entre sociedad civil y estado, y de las propias formaciones de éste y de las naciones de América Latina son ejemplos de esta aportación.
}

de combinar la economía, la política y la ideología, lo que implica que a veces se refuerce esa unidad y que en otros momentos se disuelva" (p.23).

\section{Vectores para identificar las características definitorias de América Latina}

\section{América Latina como producto del mismo camino a la modernidad}

Precisamente, en reconstrucción de esta historia, se pueden señalar los elementos que parecieran delimitar las características más evidentes de América Latina. El primero que se propone indica que América Latina es un producto del occidente europeo. En efecto, en relación con el resto del mundo en desarrollo, existe una singularidad del subcontinente latino que es flagrante: él mismo es una invención de Europa, ya que, por la conquista, entró a la esfera cultural occidental. Las civilizaciones precolombinas, en crisis para algunos en el momento de la llegada de los españoles, no resistieron en efecto a los invasores que impusieron sus lenguas, pero también sus valores y religión. Así como Roma marca a España un futuro sin improvisaciones, al latinizarla, España y Portugal marcarán en lo que se conocerá como América Latina su impronta al transmitir a las nuevas tierras este sello latino (Ruiz-Gaytan, 1992; O'Gorman, 2006).

Ese carácter europeo de las sociedades de América Latina tiene consecuencias evidentes sobre el desarrollo socioeconómico de los países involucrados. La continuidad con Occidente facilita los intercambios culturales y técnicos que no tienen ningún obstáculo lingüístico o ideológico. La fluidez de las corrientes migratorias ha multiplicado las transferencias de conocimientos y capitales.

"Si con algún movimiento fundamental de la historia ha de relacionarse la colonización de toda América Latina, es con la acumulación originaria a escala mundial" (Cuevas, 2004, p. 13). Esto implica que desde un comienzo Latinoamérica no origina su historia, sino que entre en ella llevada por Europa. El hecho de ingresar por "anexión" al concierto mundial, incorpora al análisis de su estudio la posibilidad de análisis como una comunidad social homogénea. Es este juego dialéctico el que imprime los cimientos sobre los cuales se levantaran posteriormente los actuales Estado Latinoamericanos.

Una vez anexos de una forma específica al concierto mundial, lo que le asigna un sitio determinado, América 
Latina se hace a partir de un mismo recorrido hacia la modernidad. Estas sociedades han recorrido el similar camino, con pocas variaciones, a la modernidad capitalista. Casi dos siglos de vida independiente del conjunto de naciones no pueden hacer borrar de tajo la profunda influencia de tres siglos de conquista y colonización, los cuales marcaron de manera irreversible las configuraciones sociales y labraron el singular destino de las futuras naciones, y permiten hoy en día, diferenciarlas ${ }^{8}$. Posteriormente, a partir de la independencia, los Estados del subcontinente recorren con pocas diferencias y retrasos, trayectorias paralelas en las cuales aparecen períodos claramente discernibles.

Aunque para realizar el descubrimiento y posteriormente adelantar la colonización se requería de un determinado desarrollo científico - tecnológico, lo decisivo para nuestro caso se constituía en el desarrollo capitalista y proceso de racionalización política y jurídica de los nuevos tiempos. Las profundas diferencias entre la América colonizada por Inglaterra y Francia, frente a la América colonizada por España y Portugal, se plasman en los componentes étnico, lingüístico y cultural y en un estructurar político que consolidan Estados - nacionales como entidades totalmente diferentes. El hecho de estar en manos del monarca la administración eclesiástica, evitando la secularización del Estado, contribuyó a cohesionarlo en torno a la religión como elemento tradicional de dominación que aún hoy subsiste con fuerza en Latinoamérica (Osuchowska, 2014).

La consecución de la libertad por parte del conjunto latinoamericano fue un proceso realizado a muy alto costo. No se desconoce el hecho de que la independencia haya sido una revolución política, que implicó la sustitución de una élite peninsular por una nativa, pero en difícil medida se puede afirmar que ésta fue una revolución socio económica, que se tradujo en unas nuevas realidades políticas y sociales. Por el contrario, el vacío de poder, la desvinculación de la metrópoli y precisamente la débil estructura socio - económica fragmentaria y dispersa, llevaron de manera inexorable a la desarticulación y al caudillismo.

En cuanto a la influencia norteamericana, hay que reconocer que aporta a la tradición emancipatoria,

\footnotetext{
8 Estamos sin duda en presencia de una "colonialidad del poder". Fenómeno inserto en los procesos coloniales, pero más profundo y duradero que este, en la medida que impone una determinada intersubjetividad del mundo. Se funda en la imposición de una clasificación étnica de las poblaciones, y opera en cada uno de los ámbitos de la existencia social (Quijano, 2002).
}

producto de su ruptura con Inglaterra y la forma de organización del Estado, que se expresa en las diversas copias constitucionales de los países americanos. Francia influye más en lo referente a las fuentes ideológicas y culturales, que en lo económico. El legado de la revolución es retomado: el pensamiento iluminista y los enciclopedistas, aunque restringidamente, ingresaron a América Latina.

Es viable afirmar que la proclamación de independencia se considera como el punto inicial de la conformación de los Estados nacionales en América Latina. Esto implica suponer que el nacimiento o la precaria existencia de los Estados latinoamericanos, en aquella época, se fundaban únicamente en el hecho del reconocimiento externo de su soberanía política. La independencia se puede considerar como el punto donde la comunidad latinoamericana se reclama para sí como nación y emprende la construcción del Estado, "ayudado" por los rápidos reconocimientos de las grandes potencias interesadas en su liberación, pero falto de los componentes fundamentales en su estructura.

"La ruptura del pacto colonial y la formación de los Estados nacionales implica, por lo tanto, un nuevo modo de ordenación de la economía y de la sociedad local en América Latina" (Cardozo y Faleto, 2002, p.42). Este nuevo modo de ordenación enfrenta una gran limitación objetiva que Agustín Cueva (2004) lo expresa así: "no es lo mismo construir un Estado sobre el cimiento relativamente firme del modo de producción capitalista implantado en toda la extensión de un cuerpo social, que edificarlo sobre al infructuosa topografía de estructuras precapitalistas" (p.42).

En este mismo sentido se indica: "la fase corresponde en términos generales al desarrollo de una estructura que, partiendo de una situación de equilibrio inestable de diversas formas productivas, lleve a una situación de predominio relativamente consolidado del modo de producción capitalista" (Cuevas, 2004, p.40). En lenguaje weberiano, este conflicto expresa la lucha entre el capitalismo racional e irracional, en donde sectores librecambistas encarnan el cálculo del mercado (previsibilidad), en contra de aquellos a quien un Estado tradicional otorga privilegios. El ascenso de la racionalidad se presenta en América Latina de manera similar a todas sus naciones y de una manera antagónica.

Siguiendo al gran sociólogo brasilero, Florestan Fernandes (1973), coincidimos con la siguiente tesis: "En América Latina la modernización se llevó a cabo 
de manera segmentada y según ritmos que requieren la fusión de lo moderno con lo antiguo, o de lo moderno, con lo arcaico, sucediendo lo que podría describirse como la modernización de lo arcaico y la simultánea arcaización de lo moderno" (p. 236). Este tipo específico de modernidad no rompió con el antiguo sistema colonial ni superó totalmente el posterior proceso neocolonial, lo que llevó, como se dirá mas adelante, al surgimiento y consolidación de un capitalismo dependiente.

Por ahora, cabe destacar que el primer punto de la modernización consistió en la estructuración del marco jurídico y la permanente afluencia de constituciones y leyes así lo demuestran; esta modernización se verá mediada por las estructuras tradicionales y el fuerte componente autoritario.

\section{América Latina como parte de la zona periférica y su consecuente dependencia}

Se aprecia como el conjunto que se pretende especificar se delimita en una colección de naciones y territorios que comparten la anexión forzada y el mismo camino marcado por similares faros en la modernidad. La consecuencia de esto demarca también una situación muy propia de los países de América Latina, su situación en la zona de periferia mundial. La metáfora geométrica del centro y la periferia se usa frecuentemente para describir la oposición entre los dos tipos fundamentales de lugares en un sistema espacial: el que lo domina y saca provecho de esto, el centro, y los que lo sufren, en posición periférica. Esta pareja conceptual ha sido utilizada por múltiples y variadas escuelas económicas. Los economistas de las desigualdades de desarrollo son los que le dieron su forma contemporánea (CEPAL, 1949).

Centro y periferia se diferencian porque tienen estructuras productivas diferentes: el primero se caracteriza por una estructura diversificada y homogénea; mientras que la segunda, por el contrario, posee una estructura simple y heterogénea. En el centro se genera el progreso técnico y se aplica, con lo que se beneficia de los incrementos de productividad que supone, mientras que la periferia se encuentra supeditada a los avances que se producen en el primero y se beneficia de los mismos no cuando lo quiere y necesita sino cuando se lo permiten (Prebisch, 1981).

Las relaciones entre centro y periferia se resumen en los siguientes puntos:

a) la periferia permanece retrasada por su incapacidad para generar, o integrar, el progreso técnico de la misma manera que lo hace el centro; por ello, la productividad del trabajo aumenta más lentamente en la periferia $y$, en consecuencia, los sectores productores para la exportación de materias primas, que forman la esencia de la periferia, progresan más lentamente que los sectores productores de manufacturas, que es lo característico del centro;

b) en la periferia los sectores de escasa productividad, como la agricultura de subsistencia, generan un continuo excedente de mano de obra, que presiona a la baja sobre los salarios del sector moderno lo que, además de hacer que no crezca el mercado interno, disminuye los precios del sector de exportación;

c) tanto las diferencias de productividad como la baja de los precios explican la tendencia al aumento de las diferencias entre el ingreso en el centro y la periferia;

d) se produce una tendencia al desarrollo desigual entre los polos que forman el sistema

Si nos situamos desde una perspectiva socioeconómica y geopolítica, podemos afirmar categóricamente que las naciones latinoamericanas, cualesquiera sea su nivel de riqueza y prosperidad, ocupan el mismo lugar dentro de la estructura formada por la discrepancia entre centro y periferia. Todas ellas aparecen en vías de desarrollo o de industrialización y ninguna forma parte del "centro" desarrollado. Todos dependen históricamente del mercado mundial como productores de materias primas y de bienes alimentarios. Del centro reciben tecnología, capital y los modelos culturales. Este es, sin duda, una notable particularidad e innegable factor de unidad. América Latina más que una situación, en muchos casos y con pocas excepciones, es una condición basada en el subdesarrollo y en el colonialismo.

Las naciones latinoamericanas se hacen analizables en conjunto, ya que las mayorías se han visto compelidas a asumir, dentro de su papel en la periferia, una misma estrategia de desarrollo, ya sea por dinámicas propias de la economía global o por imposición de centros externos. En este sentido, se destaca que no han existido bloques con concepciones o prácticas de desarrollo abiertamente distintas, sino que una gran mayoría han seguido "la misma ruta" dentro de una visión panorámica y general.

La dependencia se hace un hecho presente tan antiguo como su origen, como naciones independientes. Sus 
desarrollos siguen pautas enmarcadas en las relaciones coloniales y neocoloniales y que las condena a la subordinación. Es indudable que la carga de su historia limita sus potencialidades o las desvía para servir a potencias hegemónicas y que, en el presente, guía sus actividades merced a estructurales desequilibrios en las balanzas comerciales y de capital. La dependencia es la característica más constante para el llamado "Tercer Mundo". Está presente en lo cultural, en lo tecnológico, en la información, pero particularmente en lo económico y en lo político (Escobar, 1998).

Con esto no se quiere incurrir en el error de generalizar u ofrecer una explicación tan general, sin tener en cuenta las correspondientes variables históricas, en este caso, la estructura particular de las sociedades hispanas y americanas al momento de su "europeización". Tal postura llevaría a afirmar absurdos como que el actual subdesarrollo es consecuencia monocausal de la penetración capitalista, o que las inversiones extranjeras, sin ninguna diferenciación, son una forma de explotación imperialista y causa última y determinante del subdesarrollo (Sotelo, 1980).

Desafortunadamente, para el caso latinoamericano, su especificidad histórica la iguala y la dependencia la determina. Desde el inicio, la historia económica y social de América Latina se incluye dentro de un marco en el que las relaciones de dependencia desempeñan un papel primordial en la persistencia de determinadas estructuras, que se han ido reformando, pero siempre en el mantenimiento de Latinoamérica, en la posición dependiente.

A pesar de que tal circunstancia se haya identificado y haya querido corregirse, las diferencias con el mundo industrializado van ahondándose, y ya desde la mitad del siglo XIX el desnivel es tan grande, que es factible definir a Latinoamérica por su falta de estructura industrial y dentro de las necesidades e intereses de las naciones industriales. En el año de 1978, la Conferencia para el Desarrollo de la Industria, promovida por las Naciones Unidas, estableció que los países del Tercer Mundo debían tener para el año 2000 una participación del 25\% en la producción industrial mundial. Sin embargo, en el año 1984 esta participación solamente era de un 9\%.

El tema de la dependencia es clave como elemento de análisis de nuestra realidad. No son pocos los teóricos que ven en él la razón más profunda para explicar el invencible atraso y las constantes crisis y recesiones económicas. Al momento de explicar por qué América Latina no se ha podido desarrollar como otras naciones en el mismo periodo de tiempo, se ha visto que su desarrollo está condicionado por ciertas relaciones internacionales definibles como relaciones de dependencia, lo que somete este proceso a ciertas leyes específicas que lo definen.

La dependencia no es un fenómeno externo a la realidad económica latinoamericana. No es sólo el influjo de intereses extranjeros que imponen condiciones comerciales desfavorables o modelos de obligatorio seguimiento. Por el contrario, la situación de dependencia condiciona las estructuras internas de nuestros países, haciéndolos intrínsecamente dependientes. La dependencia es algo muy profundo, ligado íntimamente a mecanismos internos de funcionamiento de las sociedades latinoamericanas. Nuestro propio desarrollo, cuando está presente, es un desarrollo dependiente.

El concepto de dependencia se relaciona con este desarrollo inducido, que viene del exterior, como contrapartida a un desarrollo autónomo vinculado a lo tradicional. El desarrollo inducido depende básicamente de la demanda externa. Sus realizaciones industriales no implican el desarrollo de factores básicos. El factor dinámico viene de las exportaciones de materias primas y es, por tanto, un dinamismo dependiente.

Entre los elementos variables de la dependencia están las estructurales como la heterogeneidad de la base económica, especialización internacional, deuda externa, sistema jurídico en general y de propiedad en particular, y el peso del estado en el sistema internacional, entre otros. Entre los funcionales están el tipo y la cantidad de las exportaciones frente a las importaciones, y por tanto, los saldos en la balanza comercial y la cuenta de capitales, los pagos netos por tecnología, el déficit presupuestario, las relaciones con el FMI, acuerdos comerciales, entre otros.

Las crisis de América Latina son un reflejo y una reproducción, a niveles nacionales, de la crisis internacional. Los fenómenos de dependencia se manifiestan en ella crudamente.

\section{Núcleo de certeza positiva}

Con base en los caracteres expuestos, parece posible identificar un conjunto amplio de países del continente americano que hacen parte de la extensión del concepto de "América Latina", construido a partir del contexto establecido (anexión europea al concierto mundial, 
su recorrido similar en la modernidad y posición en la periferia - dependencia). Los mismos parecieran identificarse en su totalidad con los pertenecientes a América Central, del Sur y el Caribe.

Así, se nos presenta un conjunto demasiado heterogéneo que nos ofrece, sin duda, los casos paradigmáticos, pero que igualmente incluye muchos abiertamente discutibles por pertenecer a una zona de penumbra. Sin una mayor delimitación, se incluyen casos como la Guyana francesa o las Antillas holandesas, naciones del continente americano anexadas al concierto mundial por naciones europeas como Francia y Holanda, con un recorrido en la modernidad con patrones similares a los de sus naciones vecinas, y desde luego, pertenecientes a la periferia capitalista. No obstante, naciones que poco integran el concierto latinoamericano. Por ejemplo, y como señala Heine (1989), muchas zonas del caribe reflejan realidades muy distintas a las latinoamericanas. El legado histórico de la esclavitud, un pasado colonial reciente, economías de plantación, tamaño territorial pequeño con muy pocos recursos naturales, dan pie a una realidad muy distinta a la de los países latinoamericanos, con territorios y poblaciones de un tamaño mucho mayor, más de siglo y medio de vida independiente, un fuerte componente indígena en su población y economías diversificadas. Son patrones muy distintos en términos de pasado histórico, étnico y cultural.

Recordando la cita de Touraine, América Latina se define a partir del modo como se desarrolla y combinan las características ofrecidas, lo que implica que a veces se refuerce esa unidad y que en otros momentos se disuelva. De este modo, encontramos países que comparten modelos más homogéneos en lo social, lo político y de desarrollo, y por ende refuerzan una unidad en perjuicio de otros territorios.

En este proceso se excluyen países que, en su recorrido en la modernidad, se han diferenciado de las otras naciones. Este es el caso de aquellas que han proclamado su independencia como naciones hace relativamente poco tiempo o que, a pesar de su amplia autonomía, aún pertenecen a la mancomunidad británica o de los países bajos. Esto nos invita a delimitar más la extensión de nuestro concepto excluyendo principalmente a varias islas del Caribe y algunos territorios continentales, ya que los mismos se vinculan más con el sistema europeo que representan en ultramar, que con sus países vecinos de América Latina.
Se reconoce que el occidente europeo del descubrimiento y la conquista no fue único ni homogéneo. Como ya se afirmó, existían diferencias entre Inglaterra, Francia, España o Portugal, contrastes que se plasmaron en los territorios por ellos anexados. Los componentes étnico, lingüístico, cultural y político consolidan estados nacionales como entidades abiertamente divergentes.

Para efectos de nuestro estudio, consideramos que los países que conforman el núcleo de certeza positiva del concepto de América Latina son aquellos que heredan una tradición latina más directa, al ser conquistados por pueblos que construyeron su identidad étnico - cultural a partir de la antigua Roma y que hablan una lengua derivada del latín (lenguas romances), principalmente los españoles, franceses, italianos y portugueses, en contraste de naciones de América que se fundaron con tradición anglosajona, que se apartan históricamente de la tradición romana.

Las profundas diferencias entre la América colonizada por Inglaterra o Francia, frente a la América colonizada por España o Portugal, se plasman en los componentes étnico, lingüístico y cultural, así como en un estructurar político que consolidan Estados - nacionales como entidades totalmente diferentes, siendo más latinoamericanas aquellas correspondientes a la América hispánica, que a la América anglosajona.

Esta dispar anexión implica la relación con un interlocutor diametralmente distinto, con intercambios culturales de componente lingüístico e ideológico diferente, así como la determinación de otras corrientes migratorias. Esto las ubica en parecidas pero distintas rutas en su camino hacia la modernidad y en una posición medianamente común, pero con matices en el concierto capitalista mundial. Se diferencia entonces un amplio territorio bajo el dominio de una España y Portugal; se conforma una "América Latina" que se caracterizará por sostener durante tres siglos el poder de la península Ibérica. Evidentemente, el espíritu del capitalismo se había apoderado de Europa, pero no sobrepasando los pirineos. España y Portugal mantienen su imperio a costa de sus colonias, pero sus riquezas consolidan el surgimiento del imperio de otros.

La colonización de los inmigrantes ingleses, a diferencia de los españoles y portugueses, no solo se constituía de aventureros y buscadores sedientos de oro en cumplimiento de una empresa eminentemente monárquica. La colonización inglesa se sustenta en las familias que huyen de la persecución religiosa vigente en 
Inglaterra, familias con la tradición cultural y política de la madre del capitalismo.

Por el contrario, en los territorios que denominamos latinoamericanos de núcleo duro, una monarquía centralizada, impondrá fuertes rasgos de paternalismo, rasgos que se expresan en la noción de la colonización como una empresa personal de la Corona, que hacía que el aparato administrativo se levantara sobre bases de adhesión dinástica o por un criterio religioso católico. El fin de la corona es exclusivamente su predominio.

Launificación españolasignificódesprendersedelatécnica, la ciencia, los desarrollos jurídicos y administrativos propios de la evolución del capitalismo. En conjunto, esto se manifestará más adelante en una dirección autoritaria desde la metrópoli: "un reglamentarismo minucioso y universal que pretende operar sobre todas las fuerzas, actividades y formas" (Kaplan, 1976, p.67).

La visión de América Latina como proveedora de metales preciosos y materias primas, se percibe en la organización político - administrativa: este sistema imperial tenía su cabeza en el propio monarca, en la casa de Contratación de Sevilla y en el Consejo de Indias, y abarca todos los ámbitos de la gestión burocrática, la legislación, la justicia, el comercio, las finanzas la guerra y la religión.

En general, el efecto es descrito así por Kaplan (1976):

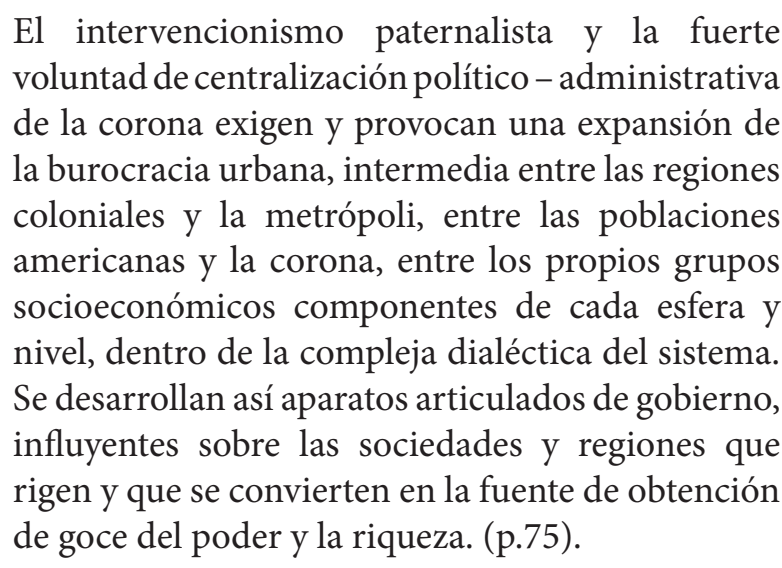

Tales diferencias se proyectarán igualmente en su vida como repúblicas independientes. Con el ideario libertario de la revolución francesa y con el ejemplo continental de los Estados Unidos de Norteamérica, las naciones del núcleo duro de certeza inician con los procesos de independencia la conformación de los Estados nacionales. Esto implica suponer que el nacimiento o la precaria existencia de los Estados Latinoamericanos en aquella época se fundaban únicamente en el hecho del reconocimiento externo de su soberanía política. La independencia se puede considerar como el punto donde la comunidad del núcleo duro latinoamericano se reclama para sí como nación y emprende la construcción del Estado, ayudado por los rápidos reconocimientos de las grandes potencias interesadas en su liberación, pero falto de los componentes fundamentales en su estructura. En palabras de Cardoso y Faleto (2002): "La ruptura del pacto colonial y la formación de los Estados nacionales implica, por lo tanto, un nuevo modo de ordenación de la economía y de la sociedad local en América Latina" (p.42).

En este contexto se entienden los conflictos generados en América Latina, que enfrentaba de una parte los intereses de las grandes potencias (de Inglaterra principalmente); de otra, los diversos intereses que los estamentos de la sociedad colonial perseguían y, por último, los de los caudillos de la independencia, no siempre linealmente correspondiente a uno o a otro sector. "La clave en estas luchas gira en torno a un conflicto básico entre las oligarquías en emergencia con pretensión hegemónica y grupos regionales, artesanales, manufactureros y comerciales, que logran cierta acumulación de capital y se orientan hacia el mercado interno" (Kaplan, 1976, p. 142).

La expresión de estos conflictos se recoge en la historia como las luchas entre unitarios y federales, conservadores y liberales, centralistas y federalistas, etc. Sus resultados son el conjunto de guerras civiles y anarquías que cubren buena parte del siglo XIX.

En este primer periodo, los países latinoamericanos emprenden la delimitación de su territorio y el desarrollo de su juridicidad. En medio de "anexiones" y "separaciones" los países expedían textos constitucionales (copiados del modelo norteamericano o francés) en busca de formalizar su establecimiento y sus nuevas fronteras. Poco a poco se va elaborando un nuevo derecho que deroga el heredado de la colonia, desarrollo inteligible solamente a través de la manera como se estructura la alianza dominante al interior de cada país.

En este contexto, los intentos de constituir el andamiaje estatal jurídico - administrativo de los nuevos países se caracterizaron, y aún se caracterizan, por ser acuerdos donde se combinan distintos grados de coacción y consenso que se traducen en pactos entre una ambigua 
estructura del Estado, que ajusta el paternalismo y el patrimonialismo con cierta dosis de burocratismo racional, eficaz y objetivo. Al respecto Kaplan Afirma:

Las etapas y características de tipo tradicional patrimonialista se confunden o se entrelazan con las de tipo burocrático. (...). El poder y la autoridad se personalizan. Su atribución y su ejercicio se fundan más en criterios de tipo personal que en criterios formales. El aparato gubernamental y administrativo recurre a notables y dignatarios más que a funcionarios en sentido estricto (p.213).

Por ahora, cabe destacar que el primer punto de la modernización consistió en la estructuración del marco jurídico y la permanente afluencia de constituciones y leyes así lo demuestran; esta modernización se verá mediada por las estructuras tradicionales y el fuerte componente autoritario del Estado, como sucedió con la división de poderes. Al respecto Kaplan anota: "La división de poderes es uno de los principios abstractos del régimen constitucional que más va siendo desvirtuado en la práctica. Los países latinoamericanos heredan del pasado y refuerzan la centralización y el poder político" (Kaplan, 1976, p. 2010).

Los Estados latinoamericanos de núcleo de certeza positiva, recogen con lujo de detalles la tradición legalista. La necesidad de institucionalizar el Estado, de reafirmar la territorialidad y legalizar la legitimidad, sumada a la creencia de que la normatividad por sí sola solucionaba los problemas, son los ingredientes de tal tendencia. Verbigracia, la aspiración de lograr un Estado nación moderno, racional administrativamente, condujo a una creación principalmente legal del derecho, a diferencia del desarrollado en otros países de creación principalmente jurisprudencial, con una mayor coherencia respecto a las condiciones sociales, políticas y estatales en las cuales se realizaba.

Respecto al proceso de burocratización, fenómeno ampliamente ligado por Weber al desarrollo del capitalismo y al destino del Estado nacional y un consecuente derecho racional, adquiere en Latinoamérica la particularidad de expresarse en función de lo que Oszlak (2007) ha definido como "(...) el dilema de orden y progreso” (p.21). Los esfuerzos encaminados a centralizar y racionalizar sus funciones se enfrentan, a cada caso, con el desarrollo del capitalismo hasta entonces logrado y la homogeneidad social alcanzada.
Todo este proceso descrito, está ausente en los países que no se incluyen en el núcleo de certeza positiva, los cuales fueron colonizados por otras potencias europeas y se hacen herederos de disímiles lenguas y costumbres. Solo hasta el 8 de diciembre de 1972, los primeros países del Caribe no hispano lograron su independencia de las viejas metrópolis, muchos años después que las naciones del continente iberoamericano, con unos procesos disímiles en su construcción como estados - nación. Mientras en el continente las colonias se liberaban a principios del siglo XIX, en el Caribe y en puntuales territorios continentales prevaleció la aquiescencia y la adhesión a los regímenes coloniales.

Su pequeña extensión, su insularidad y el componente principalmente étnico de su conflicto social, demarcan una construcción de sus estados nación, bajo una tutela férrea de la metrópoli, que solo se desvanece con los procesos descolonizadores impulsados por las Naciones Unidas bien entrado el siglo XX.

\section{Conclusión}

De las líneas expuestas, ya es posible identificar las naciones que componen el núcleo de certeza positiva de lo que llamamos América Latina, es decir, aquellas naciones que se conforman como los casos paradigmáticos de este término, sobre los cuales no cabe duda de su inclusión en la extensión del concepto. Estas son: Argentina, Bolivia, Brasil, Chile, Colombia, Costa, Rica, Ecuador, El Salvador, Guatemala, Honduras, México, Nicaragua, Panamá, Paraguay, Perú, República Bolivariana de Venezuela y Uruguay.

Las naciones más cercanas a este NCP serían los países del Caribe hispánico (Cuba, Puerto Rico, República Dominicana y Haití), países a los que es realmente problemático excluir del núcleo duro del concepto y que exigirían un análisis más detallado caso por caso. Para efectos de este estudio, el solo hecho de que no sea del todo claro su inclusión y que sea posible lanzar una sombra de duda sobre su inclusión, es suficiente para su exclusión.

Se puede proponer el siguiente cuadro clasificatorio a modo de conclusión: 


\begin{tabular}{|c|c|c|c|}
\hline \multicolumn{4}{|c|}{$\begin{array}{l}\text { América Latina y el Caribe } \\
\text { (Concepto lo más amplio posible) }\end{array}$} \\
\hline $\begin{array}{l}\text { Naciones en } \\
\text { Núcleo de } \\
\text { Certeza Positiva } \\
\text { (NCP) }\end{array}$ & \multicolumn{3}{|c|}{ Zona de Penumbra } \\
\hline \multirow{2}{*}{ América Latina } & \multicolumn{2}{|c|}{ Caribe } & \multirow{2}{*}{ Otros Territorios } \\
\hline & Caribe hispánico & Caribe no hispánico & \\
\hline Argentina & \multirow{24}{*}{$\begin{array}{c}\text { Cuba } \\
\text { Puerto Rico } \\
\text { República } \\
\text { Dominicana } \\
\text { Haití }\end{array}$} & Anguila & \multirow[t]{24}{*}{ Islas Malvinas } \\
\hline Bolivia & & Antigua y Barbuda & \\
\hline Brasil & & Antillas Neerlandesas & \\
\hline Chile & & Aruba & \\
\hline Colombia & & Bahamas & \\
\hline Costa Rica & & Barbados & \\
\hline Ecuador & & Belice & \\
\hline El Salvador & & Dominica & \\
\hline Guatemala & & Granada & \\
\hline Honduras & & Guadalupe & \\
\hline México & & Guyana & \\
\hline Nicaragua & & Guyana Francesa & \\
\hline Panamá & & $\begin{array}{l}\text { Islas Vírgenes } \\
\text { Británicas }\end{array}$ & \\
\hline Paraguay & & Islas Caimán & \\
\hline Perú & & Islas Turcas y Caicos & \\
\hline $\begin{array}{l}\text { República } \\
\text { Bolivariana de } \\
\text { Venezuela }\end{array}$ & & $\begin{array}{l}\text { Islas Virgenes de los } \\
\text { Estados Unidos }\end{array}$ & \\
\hline \multirow[t]{8}{*}{ Uruguay } & & Jamaica & \\
\hline & & Martinica & \\
\hline & & Montserrat & \\
\hline & & Saint Kitts y Nevis & \\
\hline & & Santa Lucía & \\
\hline & & $\begin{array}{l}\text { San Vicente y Las } \\
\text { Granadinas }\end{array}$ & \\
\hline & & Suriname & \\
\hline & & Trinidad y Tobago & \\
\hline
\end{tabular}

\section{Referencias}

1. Ansaldi, W. (2000). La temporalidad mixta de América Latina, una expresión de multiculturalismo. En Hobsbawm, E. (Ed.) Identidades comunitarias y democracia, (pp. 167-184). Madrid, Editorial Trotta.

2. Ardao, A. (1993). America Latina y la latinidad. Editorial: Universidad Nacional Autónoma de México, UNAM, Coordinación de Humanidades, Centro Coordinador y Difusor de Estudios Latinoamericanos, Colección 500 Años Después No. 15. México, D. F., 1993

3. Bilbao, F. (1864). El Evangelio Americano. Buenos
Aires: Imprenta de la Sociedad Tipográfica Bonaerense.

4. Cardoso, FH. y Faleto, E. (2002), Dependencia y desarrollo en América Latina. Trigésima edición. México, D.F.: Siglo XXI Editores.

5. Comisión Económica para América Latina y el Caribe (CEPAL) (1951). Estudio económico de América Latina 1949, Nueva York, Naciones Unidas. Publicación de las Naciones Unidas, No. de venta: 195 1.1I.G.1.

6. Cuevas, A. (2004) El desarrollo del capitalismo en América Latina. Ensayo de interpretación histórica. Decimonovena edición. México: Siglo XXI Editores.

7. Escobar, A. (1998). La invención del Tercer Mundo: construcción y deconstrucción del desarrollo. Bogotá, Colombia: Editorial Norma.

8. Fernandes, F. (1985), Problemas de conceptualización de las clases sociales en América Latina, en Benítez ZR., (Coord.), Las clases sociales en América Latina (pp. 191-269), México, Siglo XXI Editores.

9. Heine, J. (1989). Latinos y Antillanos: las relaciones entre America Latina y el Caribe en los noventa. Estudios Internacionales, 22(87), 298-307.

10. Kaplan, M. (1976). La formación de los Estados Nacionales en América Latina. Editorial Amorrortu, Buenos Aires.

11. Lastarria, JV. (1868). Investigaciones sobre la Influencia social de la conquista i del sistema colonial de los españoles en Chile. Miscelánea Histórica i Literaria, Tomo I, Imprenta "La Patria", Valparaíso, pp. 3- 138.

12. Martí, J. (2002). Nuestra América. Edición crítica. Investigación, presentación y notas de Cintio Vitier. Primera edición. Universidad de Guadalajara. Centro de Estudios Martianos.

13. Miro-Quesada, F. (1974). Despertar y proyecto del filosofar latinoamericano. México: Fondo de Cultura Económica.

14. O’Gorman, E. (2006). La invención de América. Investigación acerca de la estructura histórica del Nuevo Mundo y del sentido de su devenir. México: 
Fondo de Cultura Económica.

15. Osuchowska, M. (2014). La influencia de la iglesia católica en América Latina según las normas concordatarias - estudios histórico-jurídicos. Revista del CESLA. Disponible en: $<$ http://www.redalyc. org/articulo.oa? $\mathrm{id}=243333483004>$ ISSN 16414713

16. Oszlack, O. (2007) Formación histórica del Estado Latinoamericano. Elementos teórico metodológicos para su estudio, En Acuña, CH. (Comp.), Lecturas sobre el Estado y las políticas públicas: Retomando el debate de ayer para fortalecer el actual. Proyecto de Modernización del Estado, Jefatura de Gabinete de Ministros, Buenos Aires y en Estudios CEDES, Vol. 1, No 3, 1978: Buenos Aires, Argentina.

17. Prebisch, R. (1981). Capitalismo Periférico, Crisis y Transformación. Fondo de Cultura Económica, México.

18. Quijano, A. (2002). Colonialidad del poder, globalización y democracia. Revista de Ciencias Sociales de la Universidad Autónoma de Nuevo León, Año 4, Números 7 y 8, Septiembre - Abril.

19. Ribeiro, D. (1986). América Latina, a pátria grande. Rio de Janeiro: Editora Guanabara, 1986.

20. Rodó, JE. (1967). Ariel. Editado con una introducción y notas de Gordon Brotherston. Cambridge,
University Press.

21. Roig, AA. (1981). Teoría y crítica del pensamiento latinoamericano. México: Fondo de Cultura Económica.

22. Ruiz-Gaytán, B. (1992). Latinoamérica. Variaciones sobre un mismo tema. Editorial Universidad Autónoma de México. México D.F.

23. Sotelo I. (1980). América Latina: Un ensayo de interpretación. Editorial Centro de Investigaciones Sociológicas. Madrid.

24. Torres Martínez, R. (2016). Sobre el concepto de América Latina ¿Invención francesa? Cahiers d'études romanes, 32, 89-98.

25. Touraine, A. (1989). América Latina. Política y Sociedad. ed. cast.: Espasa-Calpe, S.A. Madrid.

26. Vasconcelos, J. (1927). Indología: una interpretación de la cultura ibero-americana. $2^{\text {a }}$ ed.: Agencia Mundial de Librería, Barcelona.

27. Villegas, A. (1972). Reformismo y revolución en el pensamiento latinoamericano. $1^{\text {a }}$ Edición. México: Siglo XXI Editores.

28. Zea, L. (1977). Latinoamérica Tercer Mundo. México. Editorial extemporáneo. 